\title{
El tratamiento del patrimonio bibliográfico en la biblioteca de Andalucía
}

\author{
Jerónimo Martínez González \\ Carmen Madrid Vílchez \\ Alfonso Ramos Torres \\ Biblioteca de Andalucía
}

\section{El Patrimonio Bibliográfico}

Entre las cosas con las que, en nuestro afán de permanencia, nos sobrevivimos, ocupan un lugar destacado las palabras. Se marchita la flor en pocos días, y el recuerdo del calor de la mano que nos la entregaba puede durar, quizás, toda una vida, pero las palabras llenas de sentido que la nombran ("Pura, encendida rosa/ émula de la llama...") permanecen y llegan hasta nosotros a través de un océano de siglos. Lo que Homero llama las "aladas palabras", y que, según nuestro dicho popular, "se lleva el viento" resulta ser más duro que el hierro y que la piedra.

No es, por cierto, la solidez de su soporte lo que hace permanecer a la palabra a través del tiempo; la palabra hablada es, en efecto, especialmente huidiza y pasajera.

A nuestro entender, son dos los factores, relacionados entre sí, que explican su perdurabilidad. Uno es que el lenguaje articulado es, y de forma muy notable, portador de sentido; el otro que los hombres han conseguido, a partir de los distintos tipos de escritura ideográfica y hasta los nuevas tecnologías, atrapar el sentido de las palabras en una amplia variedad de códigos y soportes que, aunque no agotan la infinidad de matices que la palabra hablada tiene en el momento de ser dicha, sí, por lo menos, conservan lo bastante de su pálpito vital como para participar de su sentido.

Los diferentes soportes han hecho posible que la historia humana esté atravesada por el fluir manso pero imparable de lo dicho; en esta atmósfera viven y crecen ideas, sentimientos y significados, es decir todo aquello que de la realidad puede decirse.

De este universo vivo nos ocupamos los bibliotecarios que tenemos que ver con el Patrimonio Bibliográfico, que está constituido originariamente por la palabra escrita.

Pero los soportes son importantes únicamente en la medida en que contribuyen a conformar el sentido completo de la obra. Nos interesan enormemente los aspectos y los detalles que particularizan, por ejemplo, un manuscrito, pero no por el afán de exclusividad del coleccionista, sino porque las señas particulares hacen a una pieza portadora de un sentido también particular $y$, por lo tanto, irreemplazable por ninguna otra en el conjunto del patrimonio a que la colectividad a la que servimos tiene derecho.

\section{Las bases legales de la gestión del Patrimonio Bibliográfico}

La ley 13/85 de 25 de junio de Patrimonio Histórico Español, expone que éste es el principal testigo de la contribución histórica de los españoles a la civilización universal y de su capacidad creativa contemporánea. La protección y el enriquecimiento de los bienes que lo integran constituyen obligaciones fundamentales que vinculan a todos los poderes públicos según el mandato que a los mismos dirige el artículo 46 de la norma constitucional.

La ley redefine el Patrimonio Histórico y amplia su extensión, comprendiendo los bienes muebles e inmuebles, el patrimonio arqueológico y el etnográfico, los museos, archivos y bibliotecas de titularidad estatal y el patrimonio documental y bibliográfico.

Establece normas que prohiben determinadas acciones y limitan ciertos usos, así como disposiciones que estimulan a su conservación, con el propósito de permitir su disfrute y facilitar su acrecentamiento. Todo ello con el fin de facilitar el acceso a la cultura de todo el pueblo.

Expresa la ley en su artículo cuarenta y nueve que forman parte del Patrimonio Documental los documentos con una antigüedad superior a los cuarenta años, generados, conservados o reunidos en el ejercicio de sus actividades por las entidades y asociaciones de carácter político, sindical o religioso y por las entidades, fundaciones y asociaciones culturales y educativas, de carácter privado. Integran asimismo el Patrimonio Documental los documentos con una antigüedad superior a los cien años, generados, conservados o reunidos por cualesquiera otras entidades particulares o personas jurídicas.

Forman parte del Patrimonio Bibliográfico las bibliotecas y colecciones bibliográficas de titularidad pública y las obras literarias, históricas, científicas o artísticas de carácter unitario o seriado, en escritura manuscrita o 
impresa, de las que no conste la existencia de al menos tres ejemplares en las bibliotecas o servicios públicos. Hace también mención la ley a la realización del censo de bienes integrantes del Patrimonio Documental y el Catálogo colectivo de los bienes integrantes del Patrimonio Bibliográfico, mediante la colaboración de la Administración del Estado y las demás administraciones competentes.

El Real Decreto I I I/86 de 10 de enero de 1986 desarrolla parcialmente la ley anterior y relaciona los datos que deberá recoger el catálogo, que, en lo referente a impresos, son:

I. título, 2. autor, 3. descripción (pie de imprenta, foliación y paginación, dimensiones, ilustraciones), 4. características especiales del ejemplar (anotaciones manuscritas, encuadernación, otras), 5. datos históricos, 6. bibliografía, 7. estado de conservación (condición, partes que faltan, restauraciones realizadas), 8. localización (comunidad autónoma, provincia, municipio, ubicación), 9. observaciones.

El 30 de marzo de 1.989 se firmó el convenio entre el Ministerio de Cultura y la Comunidad Autónoma de Andalucía para la realización del Catálogo Colectivo del Patrimonio Bibliográfico. Dicho convenio establece la aportación económica de ambas partes. También ordena que una copia de los datos recopilados y ya procesados por el Catálogo Colectivo del Patrimonio Bibliográfico Andaluz se envíe al Centro del Patrimonio Bibliográfico de la Biblioteca Nacional para su incorporación en la base de datos del Catálogo Colectivo del Patrimonio Bibliográfico Español.

La Biblioteca de Andalucía dirige y coordina el Catálogo Colectivo en nuestra Comunidad Autónoma. Para el desarrollo del mismo se convocan becas para catalogadores que se distribuyen por distintos centros, recogiendo los datos de los ejemplares anteriores a I.80I existentes en las bibliotecas. Los cuatro años anteriores, dicha labor se ha llevado a cabo en Granada y Guadix, pero con la incorporación de los próximos 25 becarios, el Catálogo Colectivo se extiende a las ocho provincias andaluzas.

\section{La descripción bibliográfica de libros antiguos}

La Descripción Bibliográfica Internacional Normalizada (ISBD) surge de una resolución del Encuentro Internacional de Expertos en Catalogación, organizado por el Comité de Catalogación de la IFLA en Copenhague en 1969, en que se establece la normalización de la forma y el contenido de la descripción bibliográfica.

El objeto principal de la ISBD es la realización de una catalogación descriptiva compatible a escala mundial para facilitar el intercambio internacional de registros bibliográficos.

En 1975 se plantea el problema de elaborar una ISBD para la catalogación de libros antiguos, es decir los pro- ducidos antes de la mecanización de la imprenta en el Siglo XIX, ya que la ISBD(M) -que se ocupa de la catalogación de publicaciones monográficas- no se adaptaba completamente a las necesidades planteadas por la descripción de libros antiguos, y en 1980 se publica la primera edición de la ISBD (A).

El propósito especifico de la ISBD (A) es suministrar transcripciones suficientemente precisas de portadas, etc., que permitan la rápida identificación de las diferentes obras y de las distintas ediciones de la misma obra.

Está dividida en 8 áreas y éstas a su vez constan de varios elementos, pero las áreas que más importancia tienen en la descripción bibliográfica de libros antiguos son:

a. Área de título y mención de responsabilidad, en la que se intenta preservar la redacción y el orden de los elementos en la portada o sustituto de portada.

b. Área de publicación, impresión o distribución, etc, que se transcribe tal y como se presenta en la portada, ya que normalmente la interrelación entre el impresor, el librero y el editor es muy estrecha, y el lugar, nombre y fecha de impresión equivalen con frecuencia a los actuales de edición, por lo que este elemento nunca es opcional.

c. Área de descripción física, en la que se debe precisar el número de hojas del ejemplar ideal, ya que en los libros antiguos, todas las hojas son importantes, incluso las que están en blanco. La extensión se expresa en términos de signaturas tipográficas, porque muchas veces no existe paginación ni foliación, y el tamaño en términos de formato y dimensiones.

d. Área de notas, que se utiliza para ampliar la descripción formal donde las normas prescritas no permiten incluir cierta información. Pueden relacionarse con cualquier aspecto de la presentación física de la publicación o de su contenido. Las referencias bibliográficas, las indicaciones de procedencia y las relativas al área de descripción física son las más comunes.

En 1987 se realiza una revisión de la $\operatorname{ISBD}(\mathrm{A})$ y se publica una nueva edición que continúa las características especiales de la primera, buscando la transcripción exacta de los títulos, siguiendo el orden de la portada siempre que sea posible, y permitiendo opciones para toda la puntuación prescrita y/o original. Además permite el uso del colofón como fuente de información prescrita.

Actualmente la automatización ha llegado también a éste tipo de fondos realizándose su catalogación en formato MARC, cuyo resultado es la creación de la base de datos del Catálogo Colectivo del Patrimonio Bibliográfico que se edita en CD-ROM por el Ministerio de Cultura y que está compuesto por los registros que se envían de todas las Comunidades Autónomas que participan en este proyecto. 